
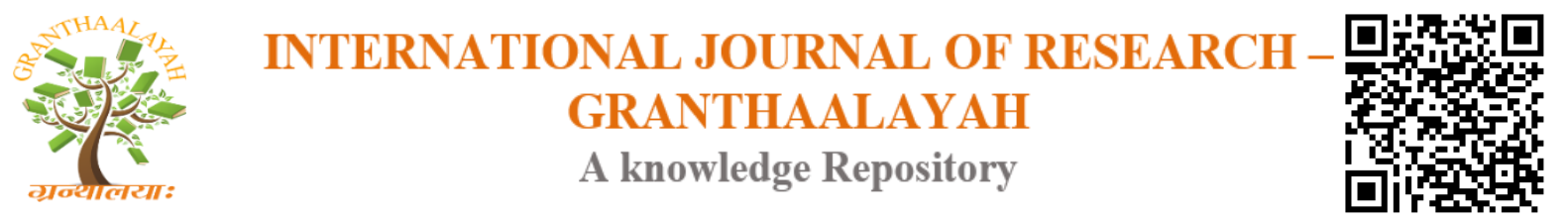

Science

\title{
ACTIVE POWER LOSS DIMINUTION \& VOLTAGE STABILITY ENHANCEMENT BY RED WOLF OPTIMIZATION ALGORITHM
}

\author{
Dr. K. Lenin *1 \\ ${ }^{* 1}$ Professor, Department of EEE Prasad V. Poultry Siddhartha Institute of Technology, \\ Kanuru, Vijayawada, Andhra Pradesh -520007, India
}

\begin{abstract}
In this paper optimal reactive power dispatch problem (ORPD), has been solved by Enriched Red Wolf Optimization (ERWO) algorithm. Projected ERWO algorithm hybridizes the wolf optimization (WO) algorithm with swarm based algorithm called as particle swarm optimization (PSO) algorithm. In the approach each Red wolf has a flag vector, and length is equivalent to the whole sum of numbers which features in the dataset of the wolf optimization (WO). Exploration capability of the projected Red wolf optimization algorithm has been enriched by hybridization of both WO with PSO. Efficiency of the projected Enriched Red wolf optimization (ERWO) evaluated in standard IEEE 30 bus test system. Simulation study indicates Enriched Red wolf optimization (ERWO) algorithm performs well in tumbling the actual power losses\& particularly voltage stability has been enriched.
\end{abstract}

Keywords: Reactive Power; Dispatch; Loss; Red Wolf Optimization; Swarm Optimization.

Cite This Article: Dr. K. Lenin. (2018). “ACTIVE POWER LOSS DIMINUTION \& VOLTAGE STABILITY ENHANCEMENT BY RED WOLF OPTIMIZATION ALGORITHM." International Journal of Research - Granthaalayah, 6(11), 355-365. https://doi.org/10.29121/granthaalayah.v6.i11.2018.1139.

\section{Introduction}

Reactive power problem plays major role in improving secure \& economic of power system operation \& control. A variety of methodologies [1-6] have been implemented to solve the problem, but difficulty found in handling the constraints. Now days various types of Evolutionary algorithms implemented to solve problem [7-15]. For last twenty years various types of programming and probabilistic based approach [16-20] has been used to solve the problem. In this work Enriched Red wolf optimization (ERWO) algorithm has been implemented to work out the problem. Both Exploration \& Exploitation has been improved. In basic Wolf optimization algorithm (WO) [21], exploration spaces are missing the diversity and the high-quality diversity is needed to upgrade the performance of the algorithm to find an optimal solution. Particle swarm optimization (PSO) [22] has good feature of exploration ability and it has been hybridized with Wolf optimization algorithm (WO) to produce an Enriched version called as Enriched Red wolf 
optimization (ERWO). PSO will aid to form better preliminary population to WO. In standard IEEE 30 bus test system efficiency of Enriched Red wolf optimization (ERWO) algorithm has been evaluated. Results indicate that Enriched Red wolf optimization (ERWO) algorithm performs well in tumbling the actual power losses\& particularly margin index value of voltage stability has been improved.

\section{Voltage Stability Evaluation}

\subsection{Modal Analysis for Voltage Stability Evaluation}

Power flow equations of the steady state system is given by,

$\left[\begin{array}{l}\Delta \mathrm{P} \\ \Delta \mathrm{Q}\end{array}\right]=\left[\begin{array}{cc}\mathrm{J}_{\mathrm{p} \theta} & \mathrm{J}_{\mathrm{pv}} \\ \mathrm{J}_{\mathrm{q} \theta} & \mathrm{J}_{\mathrm{QV}}\end{array}\right]\left[\begin{array}{l}\Delta \theta \\ \Delta V\end{array}\right]$

Where

$\Delta \mathrm{P}=$ bus real power change incrementally.

$\Delta \mathrm{Q}=$ bus reactive Power injection change incrementally.

$\Delta \theta=$ bus voltage angle change incrementally.

$\Delta \mathrm{V}=$ bus voltage Magnitude change incrementally.

Jp $\theta$, JPV , JQ $\theta$, JQV are sub-matrixes of the System voltage stability in jacobian matrix and both $\mathrm{P}$ and $\mathrm{Q}$ get affected by this.

Presume $\Delta \mathrm{P}=0$, then equation (1) can be written as,

$$
\Delta \mathrm{Q}=\left[\mathrm{J}_{\mathrm{QV}}-\mathrm{J}_{\mathrm{Q} \theta} \mathrm{J}_{\mathrm{P} \theta^{-1}} \mathrm{~J}_{\mathrm{PV}}\right] \Delta \mathrm{V}=\mathrm{J}_{\mathrm{R}} \Delta \mathrm{V}
$$

$\Delta \mathrm{V}=\mathrm{J}^{-1}-\Delta \mathrm{Q}$

Where

$\mathrm{J}_{\mathrm{R}}=\left(\mathrm{J}_{\mathrm{QV}}-\mathrm{J}_{\mathrm{Q} \theta} \mathrm{J}_{\mathrm{P} \theta^{-1}} \mathrm{JPV}\right)$

$\mathrm{J}_{\mathrm{R}}$ Denote the reduced Jacobian matrix of the system.

\subsection{Modes of Voltage Instability}

Voltage Stability characteristics of the system have been identified through computation of the Eigen values and Eigen vectors.

$\mathrm{J}_{\mathrm{R}}=\xi \wedge \eta$

Where, $\xi$ denote the right eigenvector matrix of JR, $\eta$ denote the left eigenvector matrix of $\mathrm{JR}, \wedge$ denote the diagonal eigenvalue matrix of JR.

$\mathrm{J}_{\mathrm{R}^{-1}}=\xi \wedge^{-1} \eta$ 
From the equations (5) and (6),

$\Delta \mathrm{V}=\xi \wedge^{-1} \eta \Delta \mathrm{Q}$

$\Delta V=\sum_{\mathrm{I}} \frac{\xi_{\mathrm{i}} \eta_{\mathrm{i}}}{\lambda_{\mathrm{i}}} \Delta Q$

$\xi \mathrm{i}$ denote the ith column right eigenvector $\& \eta$ is the ith row left eigenvector of JR.

$\lambda i$ indicate the ith Eigen value of JR.

reactive power variation of the ith modal is given by,

$\Delta \mathrm{Q}_{\mathrm{mi}}=\mathrm{K}_{\mathrm{i}} \xi_{\mathrm{i}}$

where,

$\mathrm{K}_{\mathrm{i}}=\sum_{\mathrm{j}} \xi_{\mathrm{ij}}{ }^{2}-1$

Where $\xi \mathrm{ji}$ is the jth element of $\xi \mathrm{i}$

ith modal voltage variation is mathematically given by,

$\Delta \mathrm{V}_{\mathrm{mi}}=\left[1 / \lambda_{\mathrm{i}}\right] \Delta \mathrm{Q}_{\mathrm{mi}}$

When the value of $|\lambda i \quad|=0$ then the ith modal voltage will get collapsed.

In equation (8), when $\Delta \mathrm{Q}=\mathrm{ek}$ is assumed, then ek has all its elements zero except the kth one being 1 . Then $\Delta \mathrm{V}$ can be formulated as follows,

$$
\Delta \mathrm{V}=\sum_{\mathrm{i}} \frac{\eta_{1 \mathrm{k}} \xi_{1}}{\lambda_{1}}
$$

$\eta_{1 \mathrm{k}}$ is $\mathrm{k}$ th element of $\eta_{1}$

At bus $\mathrm{k} \mathrm{V}-\mathrm{Q}$ sensitivity is given by,

$\frac{\partial \mathrm{V}_{\mathrm{K}}}{\partial \mathrm{Q}_{\mathrm{K}}}=\sum_{\mathrm{i}} \frac{\eta_{1 \mathrm{k}} \xi_{1}}{\lambda_{1}}=\sum_{\mathrm{i}} \frac{\mathrm{P}_{\mathrm{ki}}}{\lambda_{1}}$

\section{Problem Formulation}

Minimization of actual power loss and augmentation of static voltage stability margin index (SVSM) is main key to solve optimal reactive power dispatch problem. Voltage stability evaluation has been done through modal analysis method.

\subsection{Minimization of Real Power Loss}

Real power loss (Ploss) minimization is given as, 
$\mathrm{P}_{\text {loss }}=\sum_{\mathrm{k}=(\mathrm{i}, \mathrm{j})}^{\mathrm{n}=1} \mathrm{~g}_{\mathrm{k}\left(\mathrm{V}_{\mathrm{i}}^{2}+\mathrm{V}_{\mathrm{j}}^{2}-2 \mathrm{~V}_{\mathrm{i}} \mathrm{V}_{\mathrm{j}} \cos \theta_{\mathrm{ij}}\right)}$

Where $\mathrm{n}$ is the number of transmission lines, $\mathrm{gk}$ is the conductance of branch $\mathrm{k}, \mathrm{Vi}$ and $\mathrm{Vj}$ are voltage magnitude at bus $\mathrm{i}$ and bus $\mathrm{j}$, and $\theta \mathrm{ij}$ is the voltage angle difference between bus $\mathrm{i}$ and bus j.

\subsection{Minimization of Voltage Deviation}

Formula for reducing the voltage deviation magnitudes (VD) is derived as follows,

Minimize $\mathrm{VD}=\sum_{\mathrm{k}=1}^{\mathrm{nl}}\left|\mathrm{V}_{\mathrm{k}}-1.0\right|$

Where $\mathrm{nl}$ is the number of load busses and $\mathrm{Vk}$ is the voltage magnitude at bus $\mathrm{k}$.

\subsection{System Constraints}

Load flow equality constraints:

$P_{G i}-P_{D i}-V_{i} \sum_{j=1}^{n b} V_{j}\left[\begin{array}{cc}G_{i j} & \cos \theta_{i j} \\ +B_{i j} & \sin \theta_{i j}\end{array}\right]=0, i=1,2 \ldots, n b$

$Q_{G i}-Q_{D i}-V_{i} \sum_{j=1}^{n b} V_{j}\left[\begin{array}{cc}G_{i j} & \sin \theta_{i j} \\ +B_{i j} & \cos \theta_{i j}\end{array}\right]=0, i=1,2 \ldots, n b$

where, $n b$ is the number of buses, $\mathrm{P}_{\mathrm{G}}$ and $\mathrm{Q}_{\mathrm{G}}$ are the real and reactive power of the generator, $\mathrm{P}_{\mathrm{D}}$ and $Q_{D}$ are the real and reactive load of the generator, and $G_{i j}$ and $B_{i j}$ are the mutual conductance and susceptance between bus $i$ and bus $j$.

$\mathrm{V}_{\mathrm{Gi}}^{\min } \leq \mathrm{V}_{\mathrm{Gi}} \leq \mathrm{V}_{\mathrm{Gi}}^{\mathrm{max}}, \mathrm{i} \in \mathrm{ng}$

$\mathrm{V}_{\mathrm{Li}}^{\min } \leq \mathrm{V}_{\mathrm{Li}} \leq \mathrm{V}_{\mathrm{Li}}^{\max }, \mathrm{i} \in \mathrm{nl}$

$\mathrm{Q}_{\mathrm{Ci}}^{\min } \leq \mathrm{Q}_{\mathrm{Ci}} \leq \mathrm{Q}_{\mathrm{Ci}}^{\max }, \mathrm{i} \in \mathrm{nc}$

$\mathrm{Q}_{\mathrm{Gi}}^{\min } \leq \mathrm{Q}_{\mathrm{Gi}} \leq \mathrm{Q}_{\mathrm{Gi}}^{\max }, \mathrm{i} \in \mathrm{ng}$

$\mathrm{T}_{\mathrm{i}}^{\min } \leq \mathrm{T}_{\mathrm{i}} \leq \mathrm{T}_{\mathrm{i}}^{\mathrm{max}}, \mathrm{i} \in \mathrm{nt}$

$\mathrm{S}_{\mathrm{Li}}^{\min } \leq \mathrm{S}_{\mathrm{Li}}^{\max }, \mathrm{i} \in \mathrm{nl}$

\section{Red Wolf Optimization}

Red wolf optimization mimics the communal management and hunt deeds of Red wolves in nature. There are three fittest candidate solutions assumed as $\alpha, \beta$ and $\gamma$ to lead the population toward 
promising regions of the exploration space in each iteration of red wolf optimization. $\varphi$ is named for the rest of Red wolves and it will assist $\alpha, \beta$ and $\gamma$ to encircle, hunt, and attack prey, that is, to find Enriched solutions. In order to scientifically replicate the encompassing behavior of Red wolves, the following equations are proposed:

$\vec{G}=\left|\vec{F} \cdot \overrightarrow{Y_{P}}(t)-\vec{Y}(t)\right|$,

$\vec{Y}(t+1)=\overrightarrow{Y_{P}}(t)-\vec{H} \cdot \vec{G}$

Where $t$ indicates the current iteration, $\overrightarrow{\mathrm{H}}=2 \overrightarrow{\mathrm{b}} \cdot \overrightarrow{\mathrm{r}_{1}}-\overrightarrow{\mathrm{b}}, \overrightarrow{\mathrm{F}}=2 \cdot \overrightarrow{\mathrm{r}_{2}}, \widehat{\mathrm{Y}_{\mathrm{P}}}$ the position vector of the prey, $\vec{Y}$ is the position vector of a Red wolf, $\overrightarrow{\mathrm{b}}$ is linearly decreased from 2.0 to 0 , and $\overrightarrow{r_{1}}$ and $\overrightarrow{r_{2}}$ are arbitrary vectors in $[0,1]$.

Hunting behavior of Red wolves are mathematically simulated by following equations,

$\overrightarrow{G_{\alpha}}=\left|\overrightarrow{F_{1}}, \overrightarrow{Y_{\alpha}}-\vec{Y}\right|$

$\overrightarrow{G_{\beta}}=\left|\overrightarrow{F_{2}}, \overrightarrow{Y_{\beta}}-\vec{Y}\right|$

$\overrightarrow{G_{\gamma}}=\left|\overrightarrow{F_{3}}, \overrightarrow{Y_{\gamma}}-\vec{Y}\right|$

$\overrightarrow{Y_{1}}=\overrightarrow{Y_{\alpha}}-\overrightarrow{H_{1}} \cdot \overrightarrow{G_{\alpha}}$

$\overrightarrow{Y_{2}}=\overrightarrow{Y_{\beta}}-\overrightarrow{H_{2}} \cdot \overrightarrow{G_{\beta}}$

$\overrightarrow{Y_{3}}=\overrightarrow{Y_{\gamma}}-\overrightarrow{H_{3}} \cdot \overrightarrow{G_{\gamma}}$

$\vec{Y}(t+1)=\frac{\overrightarrow{Y_{1}}+\overrightarrow{Y_{2}}+\overrightarrow{Y_{3}}}{3}$

In this work, a new Enriched Red wolf optimization (ERWO) algorithm is proposed to solve reactive power dispatch problem \& the position of a Red wolf was updated by equation (27) \& the following equation is used to discrete the position.

flag $_{i, j}=\left\{\begin{array}{lc}1 & Y_{i, j}>0.50 \\ 0 & \text { otherwise }\end{array}\right.$

Where $\mathrm{i}$, indicates the jth position of the ith Red wolf, flag $_{i, j}$ is features of the wolf.

\section{Particle Swarm Optimization}

In Particle swarm optimization (PSO) algorithm [22] the positions and velocities of the Particles are modernized as follows:

$v_{t+1}^{i}=\omega_{t} \cdot v_{t}^{i}+c g_{1} \cdot R m_{1} \cdot\left(m_{t}^{i}-y_{t}^{i}\right)+c g_{2} \cdot R m_{2} \cdot\left(m_{t}^{g}-y_{t}^{i}\right)$

$\mathrm{y}_{\mathrm{t}+1}^{\mathrm{i}}=\mathrm{y}_{\mathrm{t}}^{\mathrm{i}}+\mathrm{v}_{\mathrm{t}+1}^{\mathrm{i}}$ 
The current position of particle is $y_{t}^{\mathrm{i}} \&$ search velocity is $v_{t}^{\mathrm{i}}$. Global best-found position is. $\mathrm{m}_{\mathrm{t}}^{\mathrm{g}}$. In uniformly distributed interval $(0,1) \mathrm{Rm}_{1} \& \mathrm{Rm}_{2}$ are arbitrary numbers. Where $\mathrm{cg}_{1}$ and $\mathrm{cg}_{2}$ are scaling parameters. $\omega_{t}$ is the particle inertia. The variable $\omega_{t}$ is modernized as

$\omega_{\mathrm{t}}=\left(\omega_{\max }-\omega_{\min }\right) \cdot \frac{\left(\mathrm{t}_{\max }-\mathrm{t}\right)}{t_{\max }}+\omega_{\min }$

Maximum and minimum of $\omega_{t}$ is represented by $\omega_{\max }$ and $\omega_{\min }$; maximum number of iterations is given by $t_{\max }$. Until termination conditions are met this process will be repeated.

\section{Enriched Red Wolf Optimization (ERWO) Algorithm for Solving Optimal Reactive Power Dispatch Problem}

In this approach red wolves $\alpha, \beta$ and $\gamma$ determine the position of the prey. $\vec{H}=2 \overrightarrow{\mathrm{b}} \cdot \overrightarrow{\mathrm{r}_{1}}-\overrightarrow{\mathrm{b}}$ Directs the exploration \& exploitation process by reducing the value from 2 to 0 . When $|\overrightarrow{\mathrm{H}}|<1$ it converged towards the prey \& If $|\overrightarrow{\mathrm{H}}|>1$ diverged away. The first best Minimum loss and variables are accumulated as " $\alpha$ " position, score $\&$ as like second best, third best accumulated as " $\beta$ " and " $\gamma$ " position \& score.

\section{Commence}

Initialize the parameters

Initialize $\mathrm{b}, \overrightarrow{\mathrm{H}}$ and $\overrightarrow{\mathrm{F}}$; beginning positions of Red wolves has been stimulated.

$\mathrm{i}=1$ : population size

$\mathrm{j}=1: \mathrm{n}$

When $(\mathrm{i}, \mathrm{j})>0.500$

(i) $=1$;

Else

(j) $=0$;

End if

End for

Work out the maximum fitness of Red wolves as follows,

Primary maximum fitness of the Red wolf is designated as " $\alpha$ "

Second maximum fitness of the Red wolf is designated as " $\beta$ "

Third maximum fitness of the Red wolf is designated as " $\gamma$ "

While $\mathrm{k}<$ maximum iteration

For $\mathrm{i}=1$ : population size

Exact Location of the existing Red wolf has been revised periodically

End for

For $\mathrm{i}=1$ : population size

For $\mathrm{i}=1: \mathrm{n}$;If $(\mathrm{i}, \mathrm{j})>0.500$

(j) $=1$;

Else

(j) $=0$;

End if

End for 
Sporadically revise the values of $b, \overrightarrow{\mathrm{H}}$ and $\overrightarrow{\mathrm{F}}$;

At this stage Fitness of Red wolves has been calculated

The assessment of red wolves " $\alpha$ ", $\beta$ " and " $\gamma$ " has to be revised

$\mathrm{k}=\mathrm{k}+1$;

End while

Re-examine the value of" $\alpha$ "as the optimal characteristic division;

End

\section{Simulated Outcomes}

The efficiency of the proposed Enriched Red Wolf Optimization (ERWO) algorithm is demonstrated by testing it on standard IEEE-30 bus system, it has 41 transmission lines of which four branches are (6-9), (6-10) , (4-12) , 6 generator buses, 24 load buses , (28-27) - are with the tap setting transformers. Optimal values of the control variables are given arte given in Table 1.

Table 1: Results of ERWO - ORPD optimal control variables

\begin{tabular}{|l|l|}
\hline List of Control variables & Variable setting values \\
\hline V1 & 1.04120 \\
V2 & 1.04020 \\
V5 & 1.04000 \\
V8 & 1.03020 \\
V11 & 1.00260 \\
V13 & 1.03020 \\
T11 & 1.0000 \\
T12 & 1.0000 \\
T15 & 1.0100 \\
T36 & 1.0100 \\
Qc10 & 2 \\
Qc12 & 3 \\
Qc15 & 2 \\
Qc17 & 0 \\
Qc20 & 2 \\
Qc23 & 2 \\
Qc24 & 3 \\
Qc29 & 2 \\
Real power loss & 4.2096 \\
SVSM & 0.2484 \\
\hline
\end{tabular}

Table 2 indicates the optimal values of the control variables $\&$ there is no limit violations in state variables. Static voltage stability margin (SVSM) has increased from 0.2484 to 0.2496. contingency analysis was conducted using the control variable setting obtained in case 1 and case 2 to determine the voltage security of the system. In Table 3 the Eigen values equivalent to contingencies are given. In Table 4Eigen value has been improved for all contingencies. Limit Violation Checking Of State Variables. Comparisons of results are shown in Table 5. 
Table 2: Results of ERWO -Voltage Stability Control Reactive Power Dispatch Optimal Control Variables

\begin{tabular}{|l|l|}
\hline List of Control Variables & Variable Setting values \\
\hline V1 & 1.04420 \\
V2 & 1.04040 \\
V5 & 1.04120 \\
V8 & 1.03040 \\
V11 & 1.00320 \\
V13 & 1.03200 \\
T11 & 0.0900 \\
T12 & 0.0900 \\
T15 & 0.0900 \\
T36 & 0.0900 \\
Qc10 & 3 \\
Qc12 & 3 \\
Qc15 & 3 \\
Qc17 & 3 \\
Qc20 & 0 \\
Qc23 & 2 \\
Qc24 & 2 \\
Qc29 & 3 \\
Real power loss & 4.9890 \\
SVSM & 0.2496 \\
\hline
\end{tabular}

Table 3: Voltage Stability under Contingency State

\begin{tabular}{|l|l|l|l|}
\hline Sl.No & Contingency & $\begin{array}{l}\text { Optimal Reactive } \\
\text { Power } \\
\text { Dispatch Setting } \\
\text { values }\end{array}$ & $\begin{array}{l}\text { Voltage Stability Control Reactive Power } \\
\text { Dispatch } \\
\text { Setting values }\end{array}$ \\
\hline 1 & $28-27$ & 0.1412 & 0.1423 \\
\hline 2 & $4-12$ & 0.1644 & 0.1652 \\
\hline 3 & $1-3$ & 0.1762 & 0.1765 \\
\hline 4 & $2-4$ & 0.2021 & 0.2054 \\
\hline
\end{tabular}

Table 4: Limit Violation Checking of State Variables

\begin{tabular}{|c|c|c|c|c|}
\hline \multirow{2}{*}{$\begin{array}{l}\text { State } \\
\text { variables }\end{array}$} & \multicolumn{2}{|l|}{ limits } & \multirow{2}{*}{$\begin{array}{l}\text { Optimal Reactive } \\
\text { Power } \\
\text { Dispatch Setting } \\
\text { values }\end{array}$} & \multirow{2}{*}{$\begin{array}{l}\text { Voltage Stability Control Reactive } \\
\text { Power Dispatch } \\
\text { Setting } \\
\text { values }\end{array}$} \\
\hline & Lower & Upper & & \\
\hline Q1 & -20.00 & 152.00 & 1.34220 & -1.32690 \\
\hline Q2 & -20.00 & 61.00 & 8.99000 & 9.82320 \\
\hline Q5 & -15.00 & 49.920 & 25.9200 & 26.0010 \\
\hline Q8 & -10.00 & 63.520 & 38.8200 & 40.8020 \\
\hline Q11 & -15.00 & 42.00 & 2.93000 & 5.0020 \\
\hline Q13 & -15.00 & 48.00 & 8.10250 & 6.0330 \\
\hline V3 & 0.950 & 1.050 & 1.03720 & 1.03920 \\
\hline
\end{tabular}




\begin{tabular}{|l|l|l|l|l|}
\hline V4 & 0.950 & 1.050 & 1.03070 & 1.03280 \\
\hline V6 & 0.950 & 1.050 & 1.02820 & 1.02980 \\
\hline V7 & 0.950 & 1.050 & 1.01010 & 1.01520 \\
\hline V9 & 0.950 & 1.050 & 1.04620 & 1.04120 \\
\hline V10 & 0.950 & 1.050 & 1.04820 & 1.04980 \\
\hline V12 & 0.950 & 1.050 & 1.04000 & 1.04660 \\
\hline V14 & 0.950 & 1.050 & 1.04740 & 1.04430 \\
\hline V15 & 0.950 & 1.050 & 1.04570 & 1.04130 \\
\hline V16 & 0.950 & 1.050 & 1.04260 & 1.04050 \\
\hline V17 & 0.950 & 1.050 & 1.03820 & 1.03960 \\
\hline V18 & 0.950 & 1.050 & 1.03920 & 1.04000 \\
\hline V19 & 0.950 & 1.050 & 1.03810 & 1.03940 \\
\hline V20 & 0.950 & 1.050 & 1.01120 & 1.01940 \\
\hline V21 & 0.950 & 1.050 & 1.04350 & 1.02430 \\
\hline V22 & 0.950 & 1.050 & 1.04480 & 1.03960 \\
\hline V23 & 0.950 & 1.050 & 1.04720 & 1.03720 \\
\hline V24 & 0.950 & 1.050 & 1.04840 & 1.03720 \\
\hline V25 & 0.950 & 1.050 & 1.01420 & 1.01920 \\
\hline V26 & 0.950 & 1.050 & 1.04940 & 1.04220 \\
\hline V27 & 0.950 & 1.050 & 1.04720 & 1.04520 \\
\hline V28 & 0.950 & 1.050 & 1.02430 & 1.02830 \\
\hline V29 & 0.950 & 1.050 & 1.04390 & 1.04190 \\
\hline V30 & 0.950 & 1.050 & 1.04180 & 1.03970 \\
\hline
\end{tabular}

Table 5: Comparison of Real Power Loss

\begin{tabular}{|l|l|}
\hline Method & Minimum loss \\
\hline Evolutionary programming [23] & 5.0159 \\
\hline Genetic algorithm [24] & 4.665 \\
\hline Real coded GA with Lindex as SVSM[25] & 4.568 \\
\hline Real coded genetic algorithm [26] & 4.5015 \\
\hline projected ERWO & 4.2096 \\
\hline
\end{tabular}

\section{Conclusion}

Enriched Red wolf optimization (ERWO) approach effectively solved the problem. Exploration \& Exploitation has been considerably improved through the proposed methodology. In standard IEEE 30 bus test system proposed technique has been tested, , comparison of the real power loss has been done \& proposed methodology reduced the actual power loss considerably with augmentation of static voltage stability margin index.

\section{References}

[1] M. A. Abido, J. M. Bakhashwain, "A novel multi objective evolutionary algorithm for optimal reactive power dispatch problem," in proc. Electronics, Circuits and Systems conf., vol. 3, pp. 1054-1057, 2003. 
[2] W. N. W. Abdullah, H. Saibon, A. A. M. Zain, K. L. Lo, "Genetic Algorithm for Optimal Reactive Power Dispatch," in proc. Energy Management and Power Delivery conf., vol. 1, pp. 160-164, 1998.

[3] K. Y. Lee, Y. M. Park, J. L. Ortiz, "Fuel-cost minimisation for both real and reactive-power dispatches," in proc. Generation, Transmission and Distribution conf., vol. 131, pp. 85-93, 1984.

[4] S. Granville, "Optimal Reactive Dispatch Trough Interior Point Methods," IEEE Trans. on Power Systems, vol. 9, pp. 136-146, 1994.

[5] N. I. Deeb, S. M. Shahidehpour, "An Efficient Technique for Reactive Power Dispatch Using a Revised Linear Programming Approach,” Electric Power System Research, vol. 15, pp. 121-134, 1988.

[6] N. Grudinin, "Reactive Power Optimization Using Successive Quadratic Programming Method," IEEE Trans. on Power Systems, vol. 13, pp. 1219-1225, 1998.

[7] M. A. Abido, "Optimal Power Flow Using Particle Swarm Optimization", Electrical Power and Energy Systems, vol. 24, pp. 563-571, 2002.

[8] A.A. Abou El Ela, M. A. Abido, S. R. Spea, "Differential Evolution Algorithm for Optimal Reactive Power Dispatch," Electric Power Systems Research, vol. 81, pp. 458-464, 2011.

[9] V. Miranda, N. Fonseca, "EPSO-Evolutionary Particle Swarm Optimization, A New Algorithm with Applications in Power Systems," in Proc. of Transmission and Distribution conf., vol. 2, pp. 745-750,2002.

[10] C.A. Canizares, A.C.Z.de Souza and V.H. Quintana, "Comparison of performance indices for detection of proximity to voltage collapse", IEEE Transactions on Power Systems, vol. 11. no.3, pp.1441-1450, Aug 1996.

[11] A. Berizzi, C. Bovo, M. Merlo, and M. Delfanti, "A ga approach to compare orpf objective functions including secondary voltage regulation”, Electric Power Systems Research, vol. 84, no. 1, pp. $187-194,2012$.

[12] C.-F. Yang, G. G. Lai, C.-H. Lee, C.-T. Su, and G. W. Chang, "Optimal setting of reactive compensation devices with an improved voltage stability index for voltage stability enhancement ", International Journal of Electrical Power and Energy Systems, vol. 37, no. 1, pp. 50 - 57, 2012.

[13] P. Roy, S. Ghoshal, and S. Thakur, "Optimal var control for improvements in voltage profiles and for real power loss minimization using biogeography based optimization," International Journal of Electrical Power and Energy Systems, vol. 43, no. 1, pp. 830 - 838, 2012.

[14] B. Venkatesh, G. Sadasivam, and M. Khan, "A new optimal reactive power scheduling method for loss minimization and voltage stability margin maximization using successive multi-objective fuzzy lp technique," IEEE Transactions on Power Systems, vol. 15, no. 2, pp. 844 - 851, may 2000.

[15] W. Yan, S. Lu, and D. Yu, "A novel optimal reactive power dispatch method based on an improved hybrid evolutionary programming technique", IEEE Transactions on Power Systems, vol. 19, no. 2, pp. 913 - 918, may 2004.

[16] W. Yan, F. Liu, C. Chung, and K. Wong, "A hybrid genetic algorithminterior point method for optimal reactive power flow", IEEE Transactions on Power Systems, vol. 21, no. 3, pp. 1163 1169, aug. 2006.

[17] J. Yu, W. Yan, W. Li, C. Chung, and K. Wong, "An unfixed piecewiseoptimal reactive power-flow model and its algorithm for ac-dc systems," IEEE Transactions on Power Systems, vol. 23, no. 1, pp. $170-176$, feb. 2008.

[18] F. Capitanescu, "Assessing reactive power reserves with respect to operating constraints and voltage stability," IEEE Transactions on Power Systems, vol. 26, no. 4, pp. 2224-2234, nov. 2011.

[19] Z. Hu, X. Wang, and G. Taylor, "Stochastic optimal reactive power dispatch: Formulation and solution method," International Journal of Electrical Power and Energy Systems, vol. 32, no. 6, pp. $615-621,2010$.

[20] A. Kargarian, M. Raoofat, and M. Mohammadi, "Probabilistic reactive power procurement in hybrid electricity markets with uncertain loads," Electric Power Systems Research, vol. 82, no. 1, pp. $68-80,2012$. 
[21] Kaveh and F. Shokohi, "Application of Grey Wolf Optimizer in design of castellated beams," Asian Journal of Civil Engineering, vol. 17, no. 5, pp. 683-700, 2016.

[22] Kennedy, J. and R.C. Eberhart, 1995. "Particle swarm optimization", Proceeding of IEEE International Conference on Neural Networks, Perth, Australia, pp: 1942-1948.

[23] Wu Q H, Ma J T. "Power system optimal reactive power dispatch using evolutionary programming", IEEE Transactions on power systems , 1995; 10(3): 1243-1248 .

[24] S.Durairaj, D.Devaraj, P.S.Kannan "Genetic algorithm applications to optimal reactive power dispatch with voltage stability enhancement”, IE(I) Journal-EL, Vol 87,September 2006.

[25] D.Devaraj, "Improved genetic algorithm for multi - objective reactive power dispatch problem", European Transactions on electrical power, 2007; 17: 569-581.

[26] P. Aruna Jeyanthy and Dr. D. Devaraj "Optimal Reactive Power Dispatch for Voltage Stability Enhancement Using Real Coded Genetic Algorithm", International Journal of Computer and Electrical Engineering, Vol. 2, No. 4, August, 2010 1793-8163

*Corresponding author.

E-mail address: gklenin@ gmail.com. 